\title{
UTILIZAÇÃO DO 111-IN OCTREOTIDE NA AVALIAÇÃO DE PATOLOGIA SECUNDÁRIA A TUMOR CARCINÓIDE
}

Allan felipe Lopes, Marcelo Cavicchioli, Eduardo Nóbrega Pereira lima, Rubens Chojniak

Trabalho realizado no Hospital do Câncer AC Camargo - São Paulo - SP

Paciente masculino, 73 anos, natural da cidade do Rio de Janeiro, médico, com queixa de dispnéia progressiva havia três meses. Apresenta como antecedentes tabagismo havia 40 anos e uma bilobectomia pulmonar (lobo médio e lobo inferior direito) havia três anos, quando foi diagnosticado tumor neuroendócrino bem diferenciado (carcinóide) e havia um ano realizadas embolizações de lesões hepáticas.

Realizou CT tórax, seguido de ressecção endoscópica de tumor endobrônquico (Figura I) havia dois meses, que evidenciou lesões ocluindo o brônquio do lobo superior direito e do lobo inferior esquerdo. Na traquéia, observou-se um conglomerado de lesões com volume muito menor, em parede lateral esquerda, até o terço médio. Na segunda intervenção, havia um mês, houve grande melhora na redução do volume tumoral e da dispnéia.

Foi submetido à cintilografia de corpo inteiro com I I IIn octreotide e spect-ct co-registrados (Figura 2), que mostrou múltiplas áreas difusas de hiperconcentração anômala do radioindicador nas projeções das regiões parietal alta à direita, parênquima pulmonar bilateralmente, mediastino, parênquima hepático, coluna vertebral, osso ilíaco bilateral e fêmures.

Tumores carcinóides são derivados de células enterocromafins e classicamente descritos como originários embriológicos dos intestinos anterior, médio e posterior.

Sua incidência é aproximadamente $0,001 \%$ e os pacientes apresentam sobrevida longa. A cintilografia com I I I-In octreotide é um exame com elevada especificidade diagnóstica, uma vez que este fármaco é um peptídeo análogo da somatostatina e seu princípio de ação é fundamentado no acoplamento desta proteína aos receptores presentes nas células de tumores carcinóides. O caso apresentado mostra tumor multifocal com metástases ósseas, hepáticas e pulmonares, o que o torna ainda mais raro.

\section{REFERÊNCIAS}

I. Vecchio S D, Camera L, Storto G, Salvatore M. Role of nuclear medicine in the diagnosis and therapy of neuroendocrine tumors. Cancer Imaging. 2004:4:SI 40-S4I.

2. Hanson MW. Scintigraphic evaluation of neuroendocrine tumors. Appl Radiol. 200 I;30: I I-7.
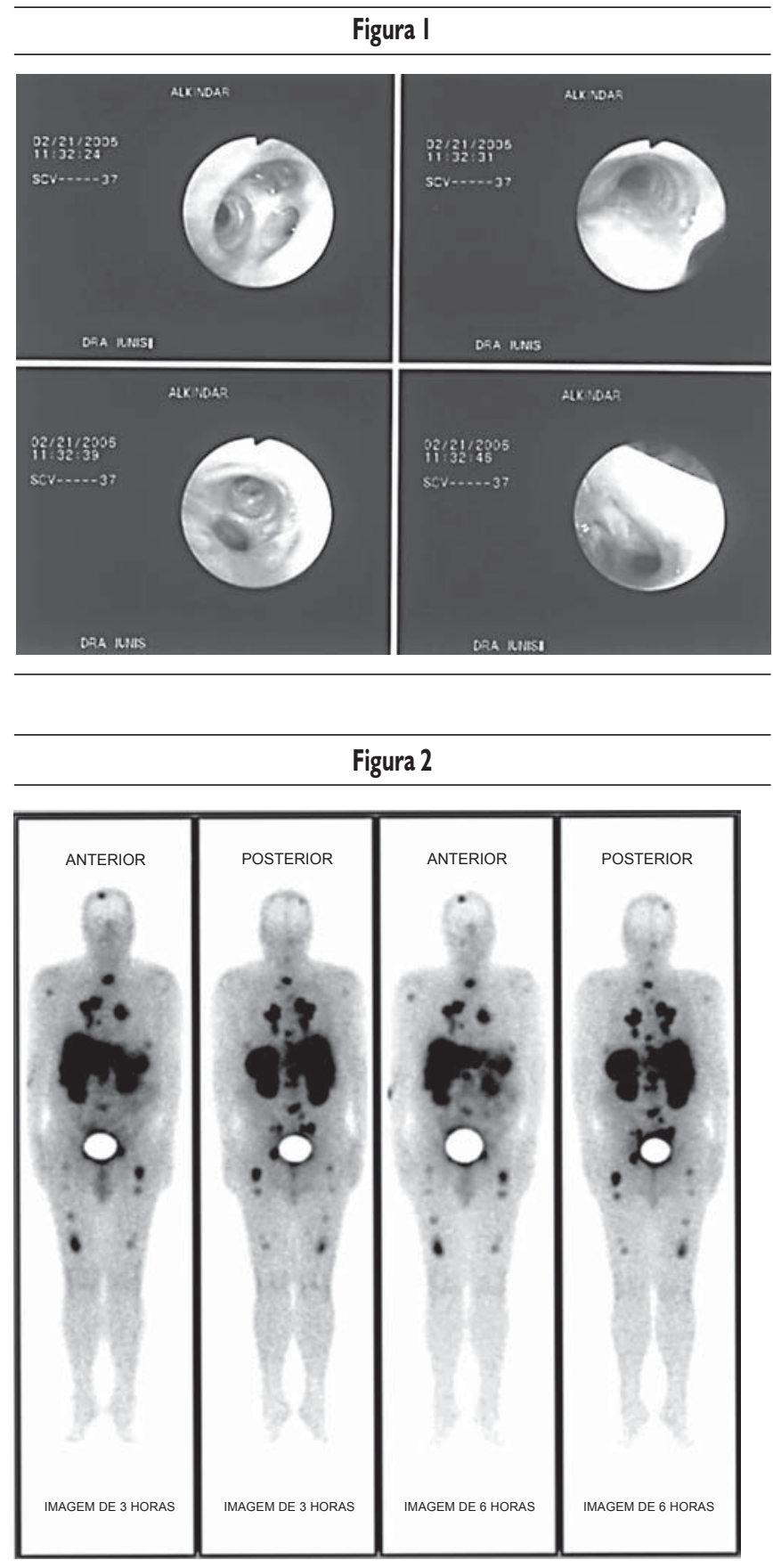